\title{
Supporting information for 'Analyzing the Evolution of Membrane Fouling via a Novel Method Based on 3D Optical Coherence Tomography Imaging
}

\author{
Weiyi $\mathrm{Li}^{\mathrm{a},}{ }^{*}$, Xin Liu ${ }^{\mathrm{a}, \mathrm{b}}$, Yi-Ning Wang ${ }^{\mathrm{a}}$, Tzyy Haur Chong ${ }^{\mathrm{a}, \mathrm{b}}$, Chuyang Y. \\ Tang $^{\mathrm{c}}$, Anthony G. Fane $\mathrm{a}^{\mathrm{a}, \mathrm{b}}$ \\ a. Singapore Membrane Technology Centre, Nanyang Technological University, Singapore \\ b. School of Civil and Environmental Engineering, Nanyang Technological University, Singapore \\ c. Department of Civil Engineering, the University of Hong Kong, Hong Kong SAR, China
}

*Corresponding author at: $\quad$ Singapore Membrane Technology Centre

Nanyang Technological University

1 Cleantech Loop, Clean Tech One

Singapore, 637141

Tel: +65 65927726

Email: wyli@ntu.edu.sg (W. Li)

\begin{abstract}
Number of pages: 4
Number of figures: 4

Number of tables: 0
\end{abstract}




\section{Figure S-1}

Scanning electron micrographs of cake layers formed during a fouling process $(10 \mathrm{kDa}$ PES membrane, TMP=1.3 bar, the foulant concentration $=0.1 \mathrm{~g} / \mathrm{L}$, the cross-flow velocity $=\sim 6 \mathrm{~cm} / \mathrm{s}$ ) with (a) silica nanoparticles and (b) bentonite particles.

(a)

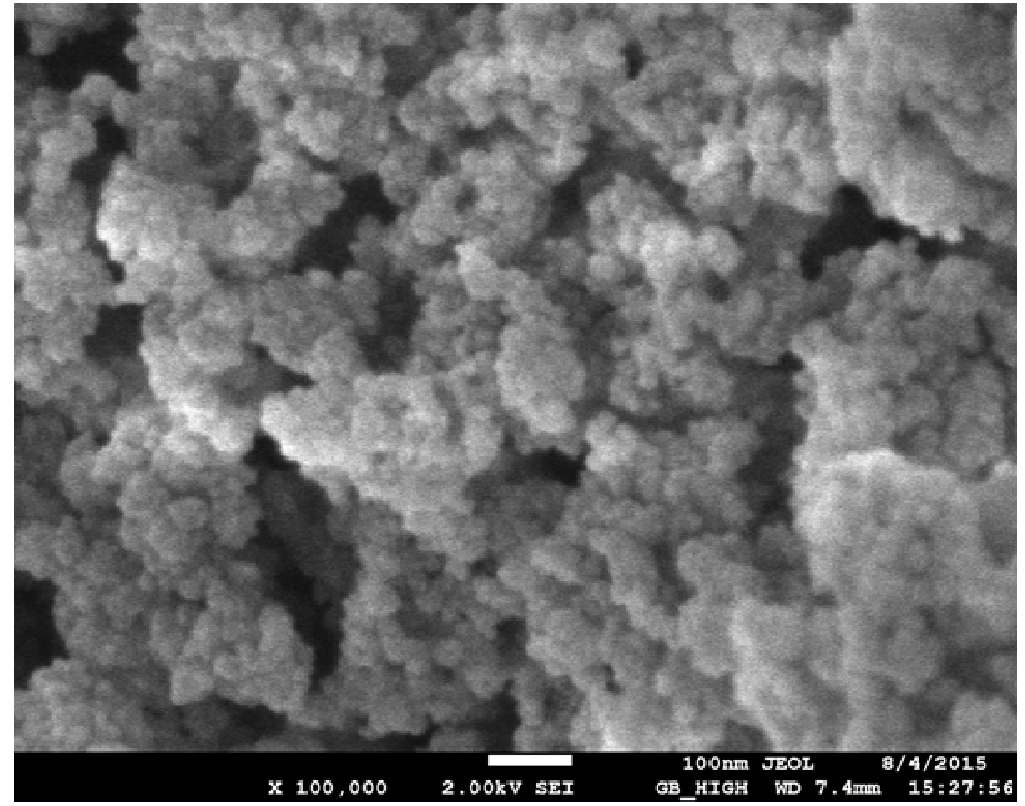

(b)

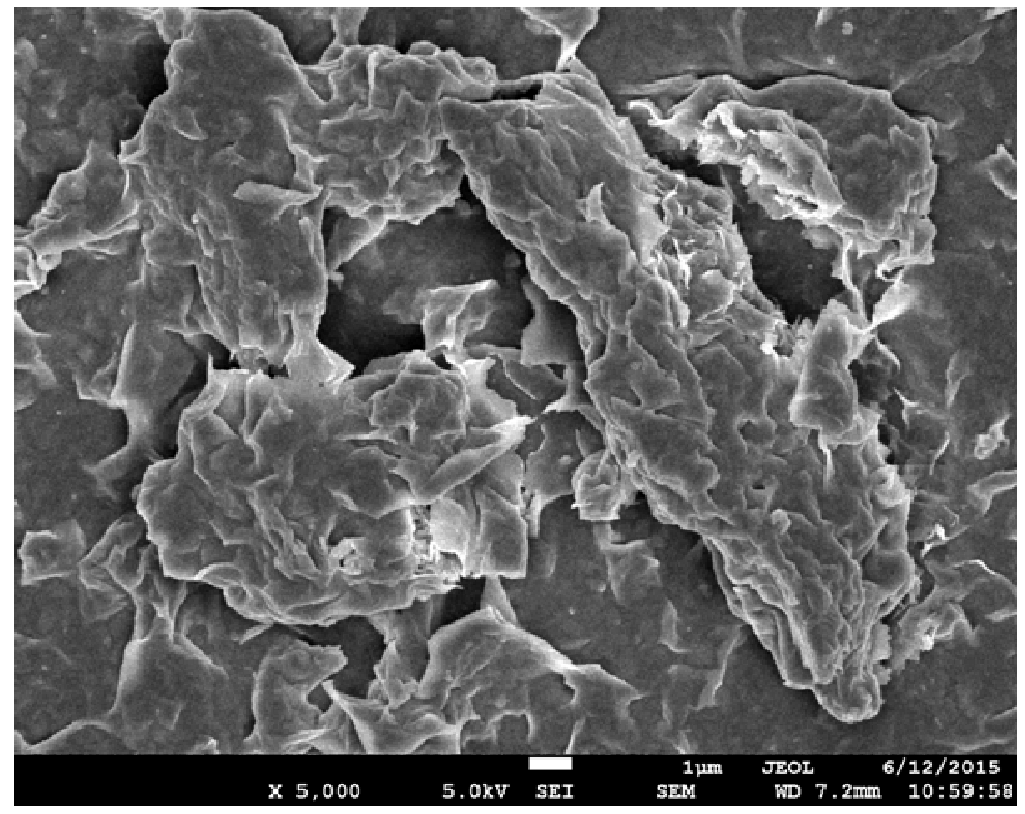




\section{Figure S-2}

Video clip showing the evolution of a cake layer within an area of $2 \mathrm{~mm} \times 2 \mathrm{~mm}$ during a fouling process (fouling duration=180 $\mathrm{min}, 10 \mathrm{kDa} P E S$ membrane, TMP=1.3 bar, the foulant concentration $=0.1 \mathrm{~g} / \mathrm{L}$, the cross-flow velocity $=\sim 6 \mathrm{~cm} / \mathrm{s}$ ) with silica nanoparticles. The grayscale indicates the local thickness of the cake layer that is normalized by the maximum. The video clip is composed of 140 frames that were generated from the OCT datasets sampled at varied rates ( $2 \mathrm{spm}$ for $\mathrm{t}=0$ to $2 \mathrm{~min}, 1 \mathrm{spm}$ for $\mathrm{t}=2$ to $90 \mathrm{~min}$, and 0.5 spm for $\mathrm{t}=90$ to $180 \mathrm{~min}$ ).

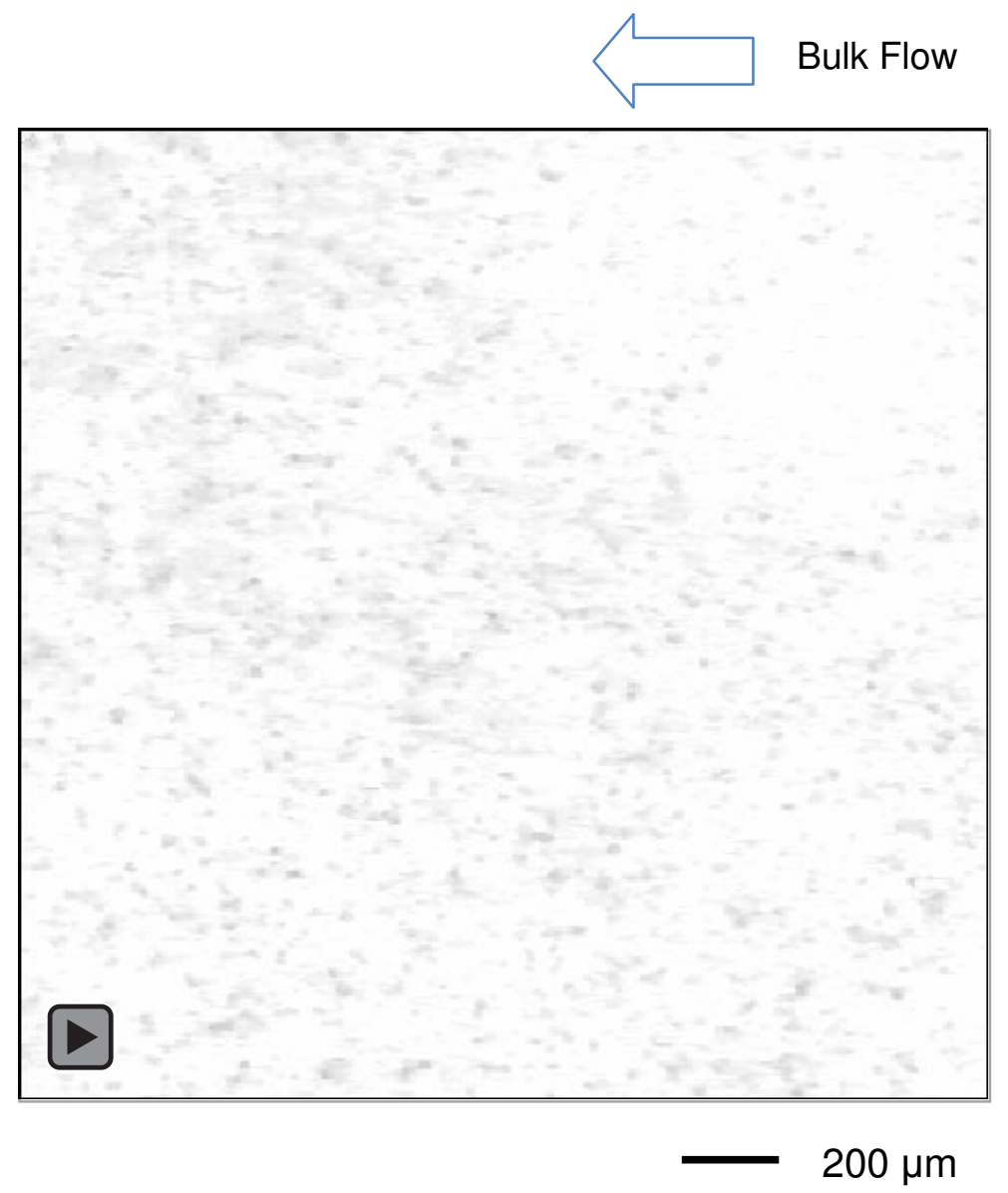




\section{Figure S-3}

Video clip showing the evolution of a cake layer within an area of $2 \mathrm{~mm} \times 2 \mathrm{~mm}$ during a fouling process (fouling duration=180 $\mathrm{min}, 10 \mathrm{kDa} P E S$ membrane, TMP=1.3 bar, the foulant concentration $=0.1 \mathrm{~g} / \mathrm{L}$, the cross-flow velocity $\sim 6 \mathrm{~cm} / \mathrm{s}$ ) with bentonite particles. The grayscale indicates the local thickness of the cake layer that is normalized by the maximum. The video clip is composed of 140 frames that were generated from the OCT datasets sampled at varied rates ( $2 \mathrm{spm}$ for $\mathrm{t}=0$ to $2 \mathrm{~min}, 1 \mathrm{spm}$ for $\mathrm{t}=2$ to $90 \mathrm{~min}$, and 0.5 spm for $\mathrm{t}=90$ to $180 \mathrm{~min}$ ).

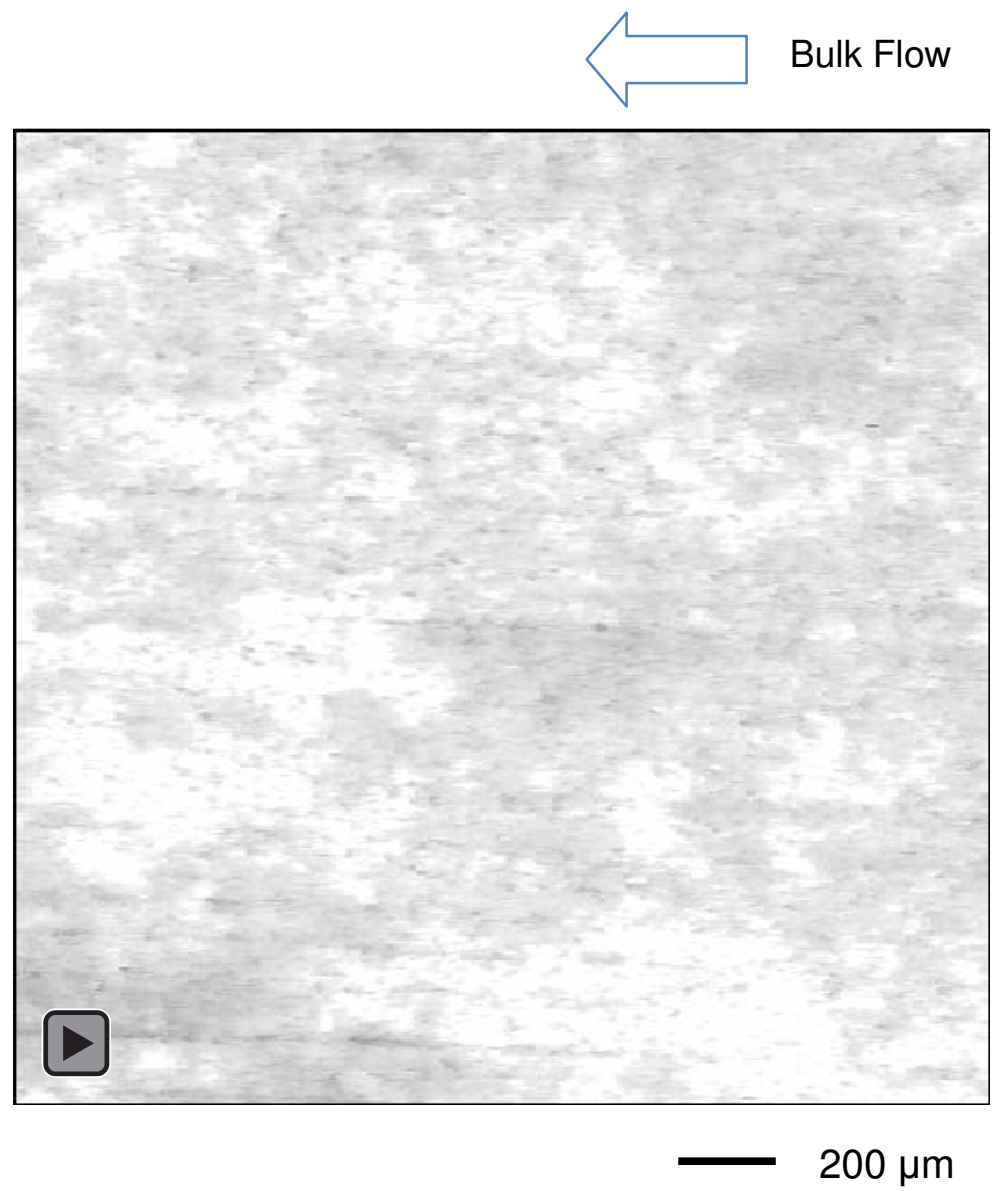




\section{Figure S-4}

Video clips showing a sequence of Doppler images overlaid with the corresponding structural images for the cross sections formed by (a) silica nanoparticles and (b) bentonite particles. The corresponding OCT datasets were sampled at the end of the fouling processes $(\mathrm{t}=180 \mathrm{~min}, 10 \mathrm{kDa}$ PES membrane, TMP=1.3 bar, the foulant concentration $=0.1 \mathrm{~g} / \mathrm{L}$, the cross-flow velocity $=\sim 6 \mathrm{~cm} / \mathrm{s}$ ); the red areas indicate the particle groups that were moving in the direction of the bulk flow, whereas the blue areas indicate the particle groups that were moving against the bulk flow. Each video clip is composed of 200 frames that were sampled at a rate of $\sim 4 \mathrm{fps}$.

(a)
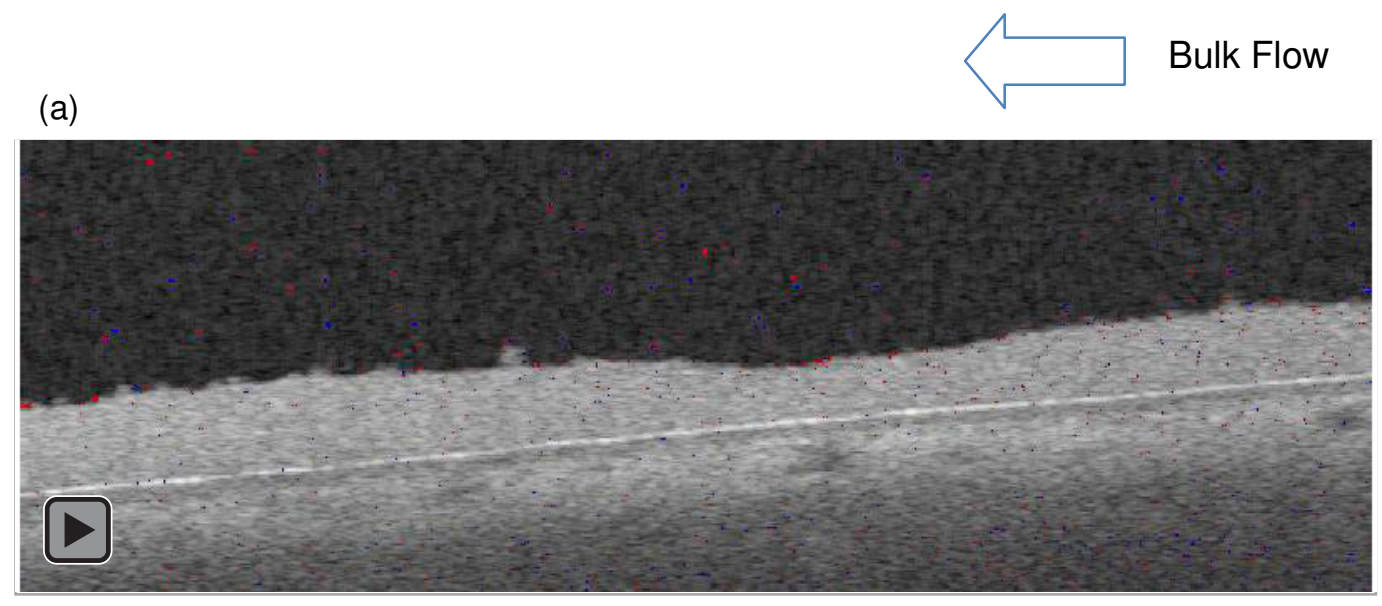

(b)

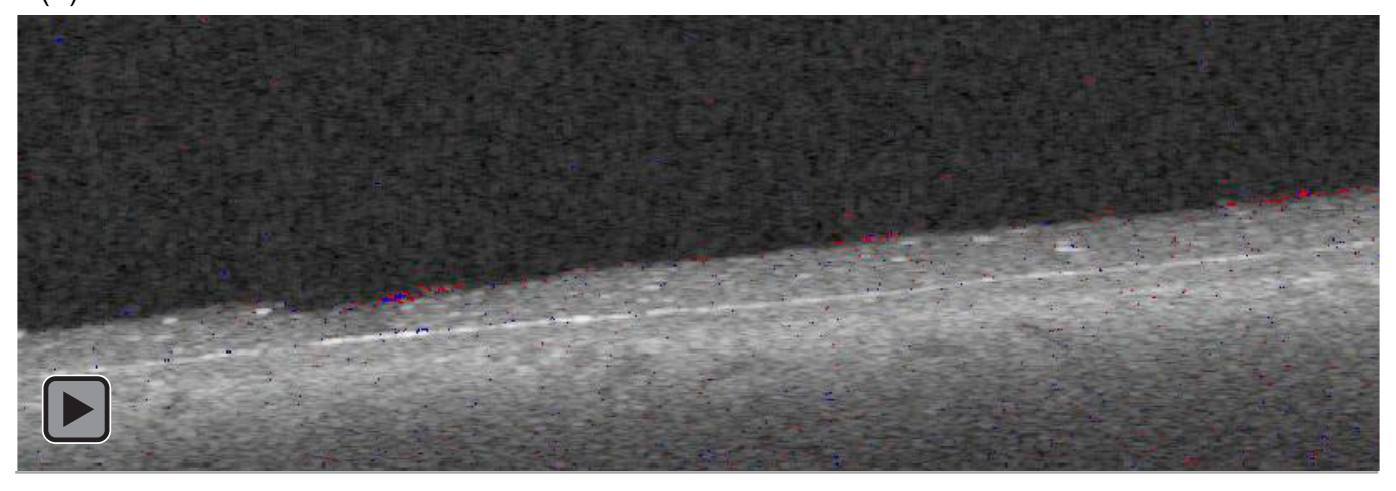

$200 \mu \mathrm{m}$ 